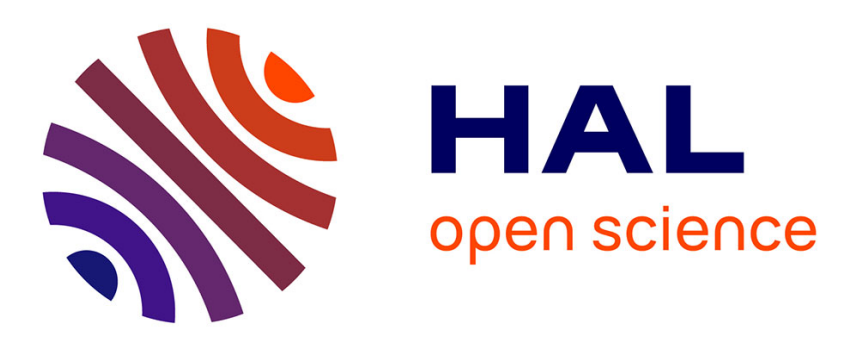

\title{
Photoionization Cross Section of the NH_2 Free Radical in the 11.1-15.7 eV Energy Range
}

Oliver Harper, Bérenger Gans, Jean-Christophe J.-C. Loison, Gustavo Garcia, Helgi Hrodmarsson, Séverine Boyé-Péronne

\section{- To cite this version:}

Oliver Harper, Bérenger Gans, Jean-Christophe J.-C. Loison, Gustavo Garcia, Helgi Hrodmarsson, et al.. Photoionization Cross Section of the NH_2 Free Radical in the 11.1-15.7 eV Energy Range. Journal of Physical Chemistry A, 2021, 125 (13), pp.2764-2769. 10.1021/acs.jpca.1c01876 . hal03197386

\section{HAL Id: hal-03197386 \\ https://hal.science/hal-03197386}

Submitted on 14 Apr 2021

HAL is a multi-disciplinary open access archive for the deposit and dissemination of scientific research documents, whether they are published or not. The documents may come from teaching and research institutions in France or abroad, or from public or private research centers.
L'archive ouverte pluridisciplinaire $\mathbf{H A L}$, est destinée au dépôt et à la diffusion de documents scientifiques de niveau recherche, publiés ou non, émanant des établissements d'enseignement et de recherche français ou étrangers, des laboratoires publics ou privés. 


\title{
Photoionization cross section of the $\mathrm{NH}_{2}$ free radical in the 11.1-15.7 eV energy range
}

\author{
Oliver J. Harper, ${ }^{* \dagger}{ }^{\dagger}$ Bérenger Gans, ${ }^{\dagger}$ Jean-Christophe Loison, ${ }^{\ddagger}$ Gustavo A. \\ Garcia, Helgi R. Hrodmarsson, $\rrbracket, \S$ and Séverine Boyé-Péronne*,† \\ $\dagger$ †niversité Paris-Saclay, CNRS, Institut des Sciences Moléculaires d'Orsay, 91405, Orsay, \\ France. \\ $\ddagger$ Institut des Sciences Moléculaires, UMR 5255 CNRS-Université de Bordeaux, Bât. A12, \\ 351 cours de la Libération, F-33405 Talence Cedex, France \\ 9Synchrotron SOLEIL, L'Orme des Merisiers, Saint Aubin BP 48, F-91192 Gif sur Yvette \\ Cedex, France \\ $\S$ Present address: Laboratory for Astrophysics, Leiden Observatory, Leiden University, \\ Leiden, The Netherlands.
}

E-mail: oliver.harper@ens-paris-saclay.fr; severine.boye-peronne@universite-paris-saclay.fr

\begin{abstract}
The $\mathrm{NH}_{2}$ radical is a key component in many astrophysical environments, both in its neutral and cationic forms, being involved in the formation of complex N-bearing species. To gain insight into the photochemical processes into which it operates and to model accurately the ensuing chemical networks, the knowledge of its photoionization efficiency is required, but no quantitative determination has been carried out so far. Combining a flow-tube H-abstraction radical source, a double imaging photoelectronphotoion spectrometer and a vacuum-ultraviolet synchrotron excitation, the absolute photoionization cross section of the amino radical has been measured in the present
\end{abstract}


work for the first time at two photon energies: $\sigma_{\text {ion }}^{\mathrm{NH}_{2}}(12.7 \mathrm{eV})=7.8 \pm 2.2 \mathrm{Mb}$ and $\sigma_{\text {ion }}^{\mathrm{NH}_{2}}(13.2 \mathrm{eV})=7.8 \pm 2.0 \mathrm{Mb}$. These values have been employed to scale the total ion yield previously recorded by Gibson et al. (JCP, 83, pp 4319-4328 (1985)). The resulting cross section curve spanning the 11.1-15.7 eV energy range will help in refining the current astrophysical models.

\section{Introduction}

The amino or amidogen radical $\left(\mathrm{NH}_{2}\right)$ is a molecule of great astrophysical interest. In a similar way to ammonia, it constitutes a building block from which more complex N-bearing species can derive (formamide $\mathrm{NH}_{2} \mathrm{CHO}$, urea $\mathrm{H}_{2} \mathrm{NCONH}_{2}$, polycyclic nitrogen-containing hydrocarbons, amino acids, proteins, etc. .). ${ }^{1,2}$ Additional reactivity can be expected from neutral $\mathrm{NH}_{2}$, an open shell species, and even more from the $\mathrm{NH}_{2}^{+}$cation which is a double radical isoelectronic to the methylene radical $\mathrm{CH}_{2} \cdot \mathrm{NH}_{2}$ is present in many astrophysical media in the gas phase, ${ }^{3-5}$ and within or in the close vicinity of solids (grains and ices), ${ }^{6,7}$ in particular comets, and is implicated in chemical reactions therein. ${ }^{7,8}$ Sandford et al. $^{6}$ reported, using laboratory experiments, the formation of pyrimidine $\left(\mathrm{C}_{4} \mathrm{H}_{4} \mathrm{~N}_{2}\right)$ in ices containing $\mathrm{H}_{2} \mathrm{O}$, $\mathrm{NH}_{3}, \mathrm{CH}_{3} \mathrm{OH}$, and $\mathrm{CH}_{4}$ following UV photolysis. They went on to expose the major role that neutral $\mathrm{NH}_{2}$ then plays in reacting with pyrimidine to form cytosine, a nucleobase. In addition, $\mathrm{NH}_{2}$ is one of the major fragments formed in the ultraviolet/vacuum-ultraviolet photodissociation of $\mathrm{NH}_{3}$, an important constituent of many astrophysical environments, including comets such as Churyumov-Gerasimenko. ${ }^{9}$

In terms of spectroscopy, neutral $\mathrm{NH}_{2}$ has been widely studied since its first observation in 1952 by Herzberg et al., ${ }^{10}$ from pure rotational ${ }^{11,12}$ to electronic studies. ${ }^{13-15}$ There are fewer works however at higher energies, around the ionization potential $(I P)$ and on the $\mathrm{NH}_{2}^{+}$ cation itself. In 1980, Dunlavey et al. ${ }^{16}$ performed the first photoelectron study on $\mathrm{NH}_{2}$, employing a He lamp and an amidogen source based on the H-abstraction reaction: $\mathrm{NH}_{3}$ $+\mathrm{F} \rightarrow \mathrm{NH}_{2}+\mathrm{HF}$. They located the three lowest electronic states of the cation $\left(\tilde{\mathrm{X}}^{+}{ }^{3} \mathrm{~B}_{1}\right.$, 
$\tilde{a}^{+1} \mathrm{a}_{1}$ and $\left.\tilde{\mathrm{b}}^{+{ }^{1}} \mathrm{~B}_{1}\right)$ and described their vibrational structure. High-lying bending modes of the two lowest electronic states of $\mathrm{NH}_{2}^{+}$were more recently investigated by Holzmeier et al. ${ }^{17}$ via threshold-photoelectron spectroscopy, using an almost identical setup to that employed in the present work. The triplet-singlet splitting between these states was studied in more detail using pulsed-field-ionization zero-kinetic-energy spectroscopy. ${ }^{18,19}$ These high resolution studies yielded a full rotational description of the two lowest electronic states of the cation, and the most precise determination to date of the ionization energy $I E\left(\mathrm{NH}_{2}\right)=$ $90083.8(10) \mathrm{cm}^{-1}(=11.1689(1) \mathrm{eV})$. The photoionization of $\mathrm{NH}_{2}$ has also been studied by accurate calculations. ${ }^{20,21}$

To our knowledge, no experimental determination of the absolute photoionization cross section of $\mathrm{NH}_{2}$ has been published until now. Only its ion yield from threshold up to $16.6 \mathrm{eV}$ has been measured by Gibson et al. ${ }^{22}$ In their study, $\mathrm{NH}_{2}$ was produced by H-addition onto $\mathrm{N}_{2} \mathrm{H}_{4}$ which initiated a set of reactions finally producing $\mathrm{NH}_{2}$. Their paper provides a detailed discussion on the thermochemistry of the $\mathrm{NH}_{x}$ compounds $(\mathrm{N}-\mathrm{H}$ bond energies and formation enthalpies) and a first determination of appearence energy of the $\mathrm{NH}_{2}$ dissociative ionization channel leading to $\mathrm{NH}^{+}(17.19 \mathrm{eV})$. A spectroscopic interpretation of the features present in the $\mathrm{NH}_{2}^{+}$ion yield is also given.

In the present paper, we report the first experimental measurement of the $\mathrm{NH}_{2}$ absolute photoionization cross section in the 11.1-15.7 eV energy range.

\section{Experimental section}

The experiments were carried out on the DESIRS beamline ${ }^{23}$ of the French synchrotron facility SOLEIL. The details of the experiment have been published previously ${ }^{24}$ and include the specificities of this setup and the procedure for determining the radical cross section, as well as detailed descriptions of energy calibrations and energy resolution. ${ }^{25,26}$ Briefly, F atoms cre- 
ated from the dissociation of $\mathrm{F}_{2}$ in a microwave discharge go on to react with helium-diluted $\mathrm{NH}_{3}$ in a flow-tube reactor. Experimental conditions are controlled via mass spectrometry to optimize the single- $\mathrm{H}$ abstraction of $\mathrm{NH}_{3}$ and to minimize all other side reactions (F addition, double-H abstraction, radical-radical reactions, etc.). After passing through two skimmers, the products from the reactor perpendicularly cross the monochromatized synchrotron radiation beam within the DELICIOUS III double imaging photoelectron/photoion spectrometer. ${ }^{27}$ The resulting ionization produces ions and electrons which are simultaneously collected using a $177 \mathrm{~V} / \mathrm{cm}$ extraction field, which ensures a $100 \%$ particle collection efficiency at the photon energies studied here. When recording ionization yield, the photon resolution was set to $\delta E=4 \mathrm{meV}$ over the whole scan range. For the absolute measurements, it was increased to $\delta E=10 \mathrm{meV}$. This difference in photon energy resolution is not however important as the fixed energy measurements were purposefully carried out in spectral regions off-resonance with any structures, thus independent of the resolution. The beamline was equipped with a gas filter containing Ar which removed any high harmonics stemming from the undulator in the final monochromatized radiation. Resulting Ar absorption lines present in the ion yield allowed the calibration of the photon energy to an accuracy of around $4 \mathrm{meV}$. The ion yield was recorded using $4 \mathrm{meV}$ energy steps in two different measurements: one from $10.8 \mathrm{eV}$ up to $14.3 \mathrm{eV}$ and one from $13.4 \mathrm{eV}$ up to $15.5 \mathrm{eV}$. The large overlap between the two scans enabled an unambiguous intensity scaling of the two measurements. A photodiode (AXUV, IRD) was used to correct the spectra from the incident VUV flux.

\section{Results and discussion}

The ion yield from this work is compared to that of Gibson et al. ${ }^{22}$ in Fig. 1. The similarities between the two spectra are clear up to $13.6 \mathrm{eV}$ and validate the measurements performed

in the present work within this spectral range. Both spectra rise characteristically slowly from the first ionization potential at $\sim 11.17 \mathrm{eV}^{19}$ to around $12.5 \mathrm{eV}$, i.e. the first excited 


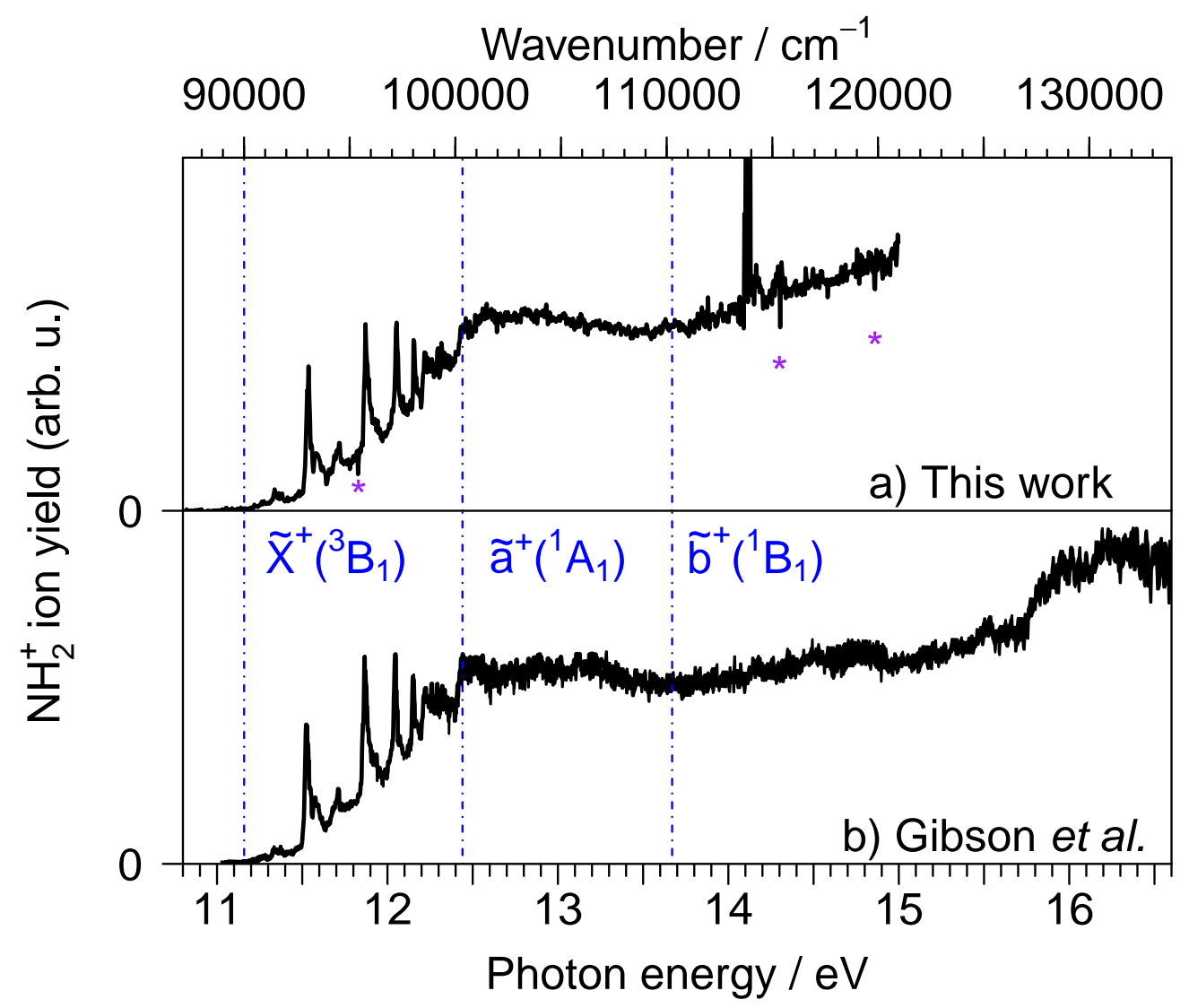

Figure 1: a) Ion yield recorded in the present work for $m / q=16$ a.m.u. and attributed mainly to the $\mathrm{NH}_{2}^{+}$cation. The off-scale sharp resonances at $14.1 \mathrm{eV}$ correspond to the atomic oxygen autoionization resonances. Purple asterisks mark Ar absorption lines from the beamline gas filter; b) $\mathrm{NH}_{2}^{+}$ion yield measured by Gibson et al. ${ }^{22}$ The blue dashed lines locate the three lowest electronic states of $\mathrm{NH}_{2}^{+} \cdot{ }^{16}$ 
state $\left(\tilde{\mathrm{a}}^{+}{ }^{1} \mathrm{~A}_{1}\right)$ of $\mathrm{NH}_{2}^{+}$. During this increase, resonances punctuate the spectrum, which can be attributed to autoionizing Rydberg states converging to the $\tilde{a}^{+}{ }^{1} \mathrm{~A}_{1}$ state. ${ }^{16}$ Above $12.5 \mathrm{eV}$, the ion yield is practically flat, but rises slightly at higher energies. In our spectrum, dominant resonances from atomic oxygen are present at around $14.1 \mathrm{eV}$. This observation shows that an $\mathrm{O}^{+}$signal issuing from $\mathrm{H}_{2} \mathrm{O}$ (see below) contaminates the $\mathrm{NH}_{2}^{+}$ion signal in our experiments, both cations being recorded in the same $m / q=16$ a.m.u. mass channel. This contamination must therefore be addressed and is discussed below. Note that the ion yield of Gibson et al. does not contain any $\mathrm{O}^{+}$contamination. In their experiment, their radicals were produced using $\mathrm{H}+\mathrm{N}_{2} \mathrm{H}_{4}$ reaction. Their $\mathrm{NH}_{2}^{+}$signal contains a contribution issuing from dissociative ionization of $\mathrm{N}_{2} \mathrm{H}_{4}$ and $\mathrm{NH}_{3}$ (side-product) above $15.7 \mathrm{eV}$. They nevertheless succeeded in correcting the $\mathrm{NH}_{2}^{+}$signal from the former process. Thus their ion yield corresponds to ionization of neutral $\mathrm{NH}_{2}$ from the $I P$ up to $15.7 \mathrm{eV}$.
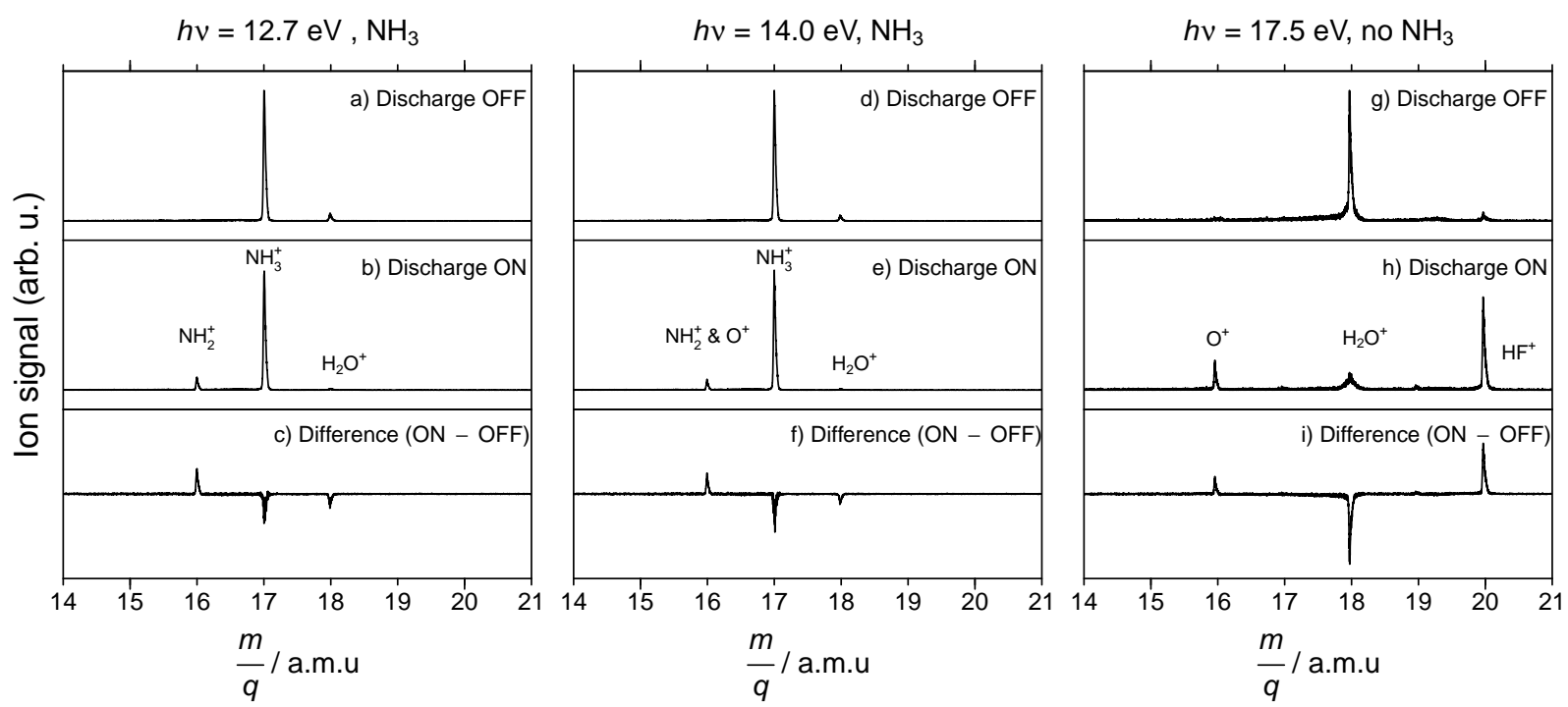

Figure 2: Panels a) to c): mass spectra recorded at $12.7 \mathrm{eV}$ with $\mathrm{NH}_{3}$ in the source and the microwave discharge turned off (panel a)), on (panel b)), and resulting difference spectrum (panel c)). Panels d) to f): same as panels a) to c) but for a photon energy of $14.0 \mathrm{eV}$. Panels g) to i): same as panels a) to c) but for a photon energy of $17.5 \mathrm{eV}$ and without $\mathrm{NH}_{3}$ injected at the source. In each column, the signal has been normalized to the most intense peak of the upper panel. See text for details. 
Typical mass spectra are displayed in Fig. 2. Panels a) to c) and panels d) to f) correspond to spectra recorded at 12.7 and $14.0 \mathrm{eV}$, respectively, and normalized to the $\mathrm{NH}_{3}^{+}$ signal obtained with the microwave discharge switched off. With the discharge turned on, the conditions were optimized to favour the production of $\mathrm{NH}_{2}$ from $\mathrm{NH}_{3}$ precursor whilst minimizing parasitic reactions. In particular, the absence of $\mathrm{NH}^{+}$at $m / q=15$ a.m.u. in the $14.0 \mathrm{eV}$ spectra (panels e) and f)) (i.e. above $I E(\mathrm{NH})=13.480 \mathrm{eV}^{24}$ ) shows that $\mathrm{NH}$ is not produced in the reactor via double-H abstraction. ${ }^{25}$ As seen in panels a) to f) of Fig. 2, water is present as an impurity in the experiment, and it is almost completely consumed when the F-atom-producing discharge is turned on (panels b) and e)). It could lead to the formation of $\mathrm{OH}$ via the parasitic reaction $\mathrm{H}_{2} \mathrm{O}+\mathrm{F} \rightarrow \mathrm{OH}+\mathrm{HF}$ which could then contaminate the $\mathrm{NH}_{3}^{+}$signal at $m / q=17$ a.m.u. rendering the exploitation of the mass spectra difficult if not impossible. For this reason, additional mass spectra were recorded, within the same conditions but without any $\mathrm{NH}_{3}$, at a photon energy of $17.5 \mathrm{eV}$ to be above the $I P$ of any potentially produced fragments, including $\mathrm{HF}\left(\operatorname{IE}(\mathrm{HF})=16.03 \mathrm{eV}^{28}\right)$ the by-product of $\mathrm{H}$ abstractions by F. They are displayed in the right-hand panels of Fig. 2 (panels g) to i)). Note that in this case the mass signals have been normalized to that of $\mathrm{H}_{2} \mathrm{O}^{+}$recorded without discharge (panel g)). This explains the amplified appearance of the water peak although the abundance of neutral water is the same as in the two left columns. Since the photoionization cross section of water at $17.5 \mathrm{eV}$ is about twice as large as at $14.0 \mathrm{eV}$, see ref. 29, the normalized signals observed in panels g) and h), in particular at $m / q=16$ a.m.u., are actually very weak compared to those of panels d) and e). These ammonia-free spectra show that water is consumed by switching the discharge on (panels h) and i)), pointing towards a contamination upstream from the microwave discharge on the $\mathrm{F}_{2}$ gas line. The difference spectrum of panel i) illustrates the consumption of $\mathrm{H}_{2} \mathrm{O}$ and production of $\mathrm{O}$ and $\mathrm{HF}$ $\left(\mathrm{H}_{2} \mathrm{O}+2 \mathrm{~F} \rightarrow \mathrm{O}+2 \mathrm{HF}\right)$. In the presence of $\mathrm{NH}_{3}$, atomic fluorine reacts mainly with $\mathrm{NH}_{3}$ giving $\mathrm{HF}+\mathrm{NH}_{2}\left(k=10^{-10} \mathrm{~cm}^{3} \cdot \mathrm{s}^{-1}\right.$ at $298 \mathrm{~K}$, see Ref. 30). As the reaction rates of $\mathrm{OH}+\mathrm{NH}_{3}$ and $\mathrm{OH}+\mathrm{NH}_{2}$ are low at room temperature $\left(k=1.6 \cdot 10^{-13} \mathrm{~cm}^{3} . \mathrm{s}^{-1}\right.$ and $\sim 10^{-12} \mathrm{~cm}^{3} \cdot \mathrm{s}^{-1}$, 
respectively), ${ }^{31} \mathrm{OH}$ will mainly react either with atomic fluorine to give $\mathrm{O}+\mathrm{HF}$ or on the walls, but it will not react with $\mathrm{NH}_{3}$ or $\mathrm{NH}_{2}$. Moreover, very little $\mathrm{OH}$ radical is left by the time the molecules enter the spectrometer and are ionized by the synchrotron radiation, likely because they are produced close to the discharge and undergo self-reactions (producing $\mathrm{O}$ and $\mathrm{H}_{2} \mathrm{O}$ ), reaction with $\mathrm{O}$ atoms (yielding $\mathrm{O}_{2}$ ) or reactions on the walls. The presence of $\mathrm{OH}$ in the experiment can only be detected at energies above the $I P(13.0170 \mathrm{eV}),{ }^{32}$ hence it would have no consequences in the absolute values at $12.7 \mathrm{eV}$. In the present work, no $\mathrm{OH}$ is detected even above $13.0170 \mathrm{eV}$ as shown by the identical curves in Fig. 1. Oxygen atoms self-react producing $\mathrm{O}_{2}$ and there also seems to be some reactivity with $\mathrm{N}_{2}$ impurity producing NO (both products identified via the recording of their ion yield). ${ }^{25}$ The absence of $m / q=17$ a.m.u. in the spectra of panels h) and i) of Fig. 2 further demonstrates that there is no contamination of the $\mathrm{NH}_{3}^{+}$signal by that of $\mathrm{OH}^{+}$in the experiment. The presence of $\mathrm{O}$ atoms in the experiment is however confirmed, which will induce a contamination of the $\mathrm{NH}_{2}^{+}$signal at $m / q=16$ a.m.u. for photon energies above $I E(\mathrm{O})=13.61 \mathrm{eV},{ }^{33}$ and will thus require that reliable absolute measurements be performed below $13.61 \mathrm{eV}$.

Absolute measurements of the $\mathrm{NH}_{2}$ photoionization cross section were thus undertaken at two energies, 12.7 and $13.2 \mathrm{eV}$ located on a plateau (see Fig. 1), to probe the $\mathrm{NH}_{2}$ cross section over a greater range, thus improving the precision. The procedure is the same as used in a previous work on the $\mathrm{OH}$ radical. ${ }^{25,34,35}$ The difference between mass spectra recorded with the discharge on and mass spectra with the discharge off is a depletion of $m / q=17$ a.m.u. signal in favor of $m / q=16$ a.m.u.. This change is the result of the consumption of $\mathrm{NH}_{3}$ by $\mathrm{F}$ atoms producing $\mathrm{NH}_{2}$. Applying matter conservation to the number densities, we have $\Delta\left(n_{\mathrm{NH}_{3}}\right)=n_{\mathrm{NH}_{3}}^{\mathrm{off}}-n_{\mathrm{NH}_{3}}^{\mathrm{on}}=n_{\mathrm{NH}_{2}}^{\mathrm{on}} . \mathrm{As}_{\mathrm{NH}_{2}^{+}}^{+}$and $\mathrm{NH}_{3}^{+}$are neighboring masses, we assume that their transmission and detection efficiencies are the same. We also neglect any wall loss of $\mathrm{NH}_{2}$. In order to verify this, we measured the ratio of produced $\mathrm{NH}_{2}$ with respect to the quantity of consumed $\mathrm{NH}_{3}$ whilst varying the injector distance. We found this ratio to be 
independent of the injector distance which confirms that $\mathrm{NH}_{2}$ is not lost to the walls within our reaction times. The proportionality law between ion signal, number of irradiated species and photoionization cross sections thus leads to:

$$
\sigma_{\mathrm{NH}_{2}}^{\text {ion }}=\sigma_{\mathrm{NH}_{3}}^{\text {ion }} \times \frac{S_{\mathrm{NH}_{2}^{+}}}{\Delta\left(S_{\mathrm{NH}_{3}^{+}}\right)}
$$

In Eq.(1), $\Delta\left(S_{\mathrm{NH}_{3}^{+}}\right)$and $S_{\mathrm{NH}_{2}^{+}}$are measured experimentally from the mass spectra. The $\mathrm{NH}_{3}$ photoionization cross section is well known. ${ }^{36,37}$ We used the values of Samson et al. ${ }^{36}$ of $8.88 \pm 0.27$ and $8.20 \pm 0.25 \mathrm{Mb}$ at 12.7 and $13.2 \mathrm{eV}$, respectively, and considered the stated accuracy on these values of $3 \%$ as being $2 \sigma$ accuracy. The $\mathrm{NH}_{2}$ photoionization cross section uncertainty was then derived via a Monte Carlo uncertainty propagation procedure applied on Eq.(1). We found: $\sigma_{\text {ion }}^{\mathrm{NH}_{2}}(12.7 \mathrm{eV})=7.8 \pm 2.2 \mathrm{Mb}$ and $\sigma_{\text {ion }}^{\mathrm{NH}_{2}}(13.2 \mathrm{eV})=7.8 \pm 2.0 \mathrm{Mb}$.

These absolute measurements were further used to set the $\mathrm{NH}_{2}^{+}$ion yield of Gibson et al. ${ }^{22}$ to an absolute scale up to $15.7 \mathrm{eV}$. The resulting curve is displayed in Fig. 3. Error bars were evaluated by taking the relative uncertainty at each of the two fixed energy measurements and propagating them over the whole scan range. The given final uncertainty, represented as light blue error bars in Fig. 3, is the minimum relative uncertainty of the two. A third absolute measurement performed at $14 \mathrm{eV}$ is reported on this curve without any attempt to correct it from the expected oxygen contamination: $\sigma_{\text {ion }}^{m / q=16}(14.0 \mathrm{eV})=8.1 \pm 3.2 \mathrm{Mb}$. It constitutes an upper estimate of the $\mathrm{NH}_{2}$ cross section (Eq.(1)). The corresponding value lies within the estimated error bars and is still in excellent agreement with the scaled ion yield, indicating that the $\mathrm{O}^{+}$contribution has a negligible impact on the cross section determination. Nevertheless note that this point was not employed in the absolute scaling procedure. 


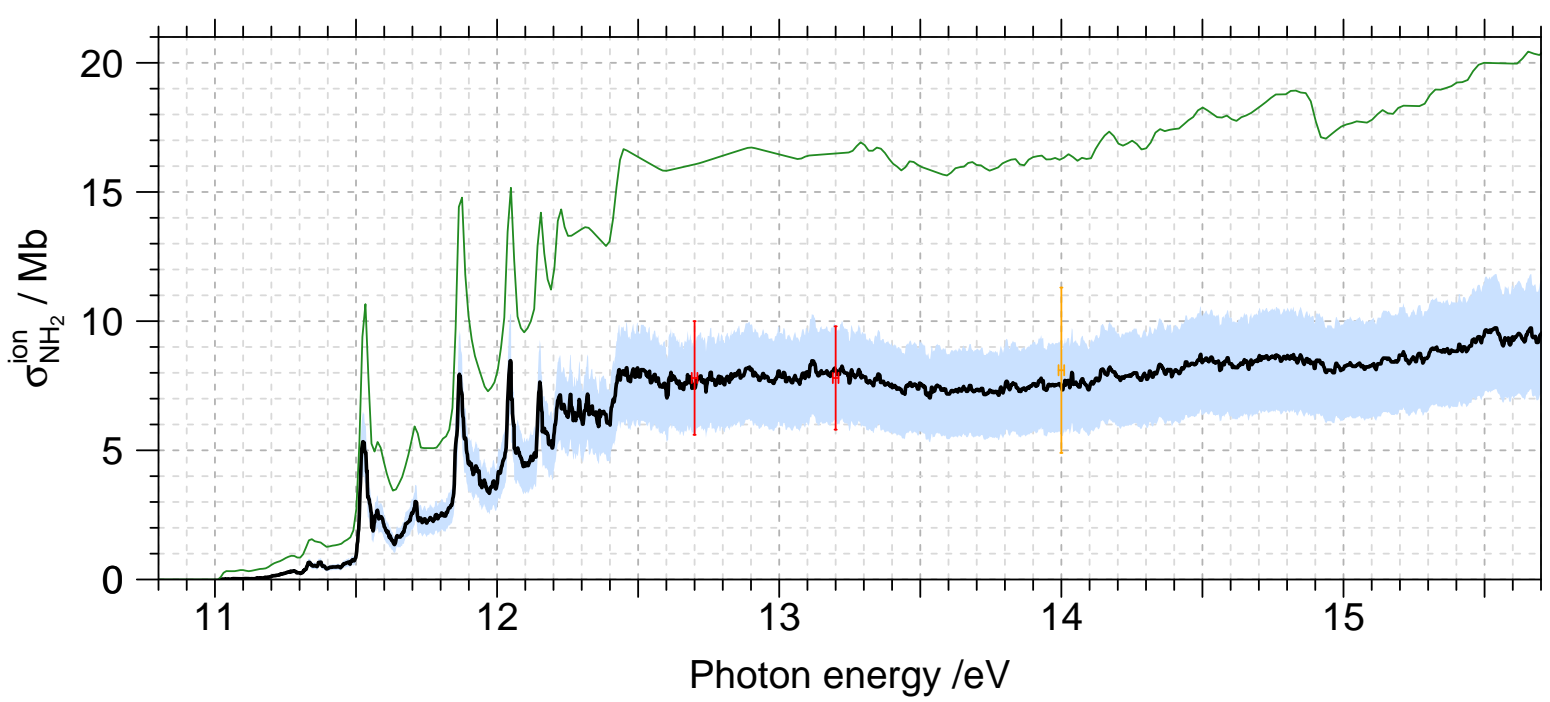

Figure 3: The $\mathrm{NH}_{2}^{+}$ion yield of Gibson et al. ${ }^{22}$ scaled to an absolute photoionization cross section from threshold up to $15.7 \mathrm{eV}$. The absolute measurements undertaken in this work at $12.7,13.2$ and $14.0 \mathrm{eV}$ are depicted as red and orange crosses along with their associated $2 \sigma$ error bars. The light blue area represents $2 \sigma$ error bars carried over the whole study range. The green curve recalls the cross section used in the Leiden astrophysical database. ${ }^{38}$

\section{Concluding remarks}

The newly measured cross section values of this work can be compared to those available in databases dedicated to astrophysical models. For instance the Leiden database ${ }^{38}$ proposes $\mathrm{NH}_{2}$ photoionization cross section values using the ion yield of Gibson et al. ${ }^{22}$ that is arbitrarily set to $20 \mathrm{Mb}$ at $15.5 \mathrm{eV}$ to be in line with other molecules of their database. As shown in Fig. 3 where the resulting curve is displayed in green, this scaling factor overestimates cross section values by about a factor 2 and thus leads to an overestimation of the $\mathrm{NH}_{2}$ photoionization process in models relying on this database. The correction of this overestimation might lead to a greater predicted abundance of neutral $\mathrm{NH}_{2}$ in different regions testifying to an increased importance of $\mathrm{NH}_{2}$ as a reactive intermediate in photodissociation regions as well as protoplanetary and protostellar envelopes where UV radiation and cosmic ray ionization is plentiful. ${ }^{39}$ The present work illustrates the importance of an accurate determination of VUV photoionization cross sections of astrophysical species, especially of free radicals, in order to refine photochemical models. 
Our measured values will be particularly useful in any laboratory experiments using massspectrometry coupled with single-photon ionization to derive quantitative data (e.g. branching ratio measurements of photodissociation channels following the experimental scheme of Ref. 40).

Finally, this first experimental measurement of the $\mathrm{NH}_{2}$ photoionization cross section opens new possibilities for deriving that of the $\mathrm{NH}$ radical, which has also been detected in comets, ${ }^{41}$ in the sun, ${ }^{42}$ or in the interstellar media. ${ }^{43}$ The NH cross-section has yet to be reported, but is achievable with this setup by tuning the flow-tube conditions to allow both a single- and a double- $\mathrm{H}$ abstractions. This operation mode is more challenging, but will be attempted in a future experimental campaign.

\section{Acknowledgement}

This work has received financial support from the French Agence Nationale de la Recherche (ANR) under Grant No. ANR-12-BS08-0020-02 (project SYNCHROKIN). The experiments were performed on the DESIRS Beamline at SOLEIL under Proposal Number 20181543. We are grateful to the entire staff of SOLEIL for running the facility. This work was supported by the Programme National "Physique et Chimie du Milieu Interstellaire" (PCMI) of CNRS/INSU with INC/INP co-funded by CEA and CNES. H.R.H. is grateful for the support from the Marie Sklodowska Curie actions, proposal ID: 838372.

\section{Supporting Information Available}

See supplementary material for the photoionization cross section data of $\mathrm{NH}_{2}$ as a function of photon energy from 11.1 to $15.7 \mathrm{eV}$. 


\section{References}

(1) Enrique-Romero, J.; Rimola, A.; Ceccarelli, C.; Ugliengo, P.; Balucani, N.; Skouteris, D. Reactivity of $\mathrm{HCO}$ with $\mathrm{CH}_{3}$ and $\mathrm{NH}_{2}$ on Water Ice Surfaces. A Comprehensive Accurate Quantum Chemistry Study. ACS Earth and Space Chemistry 2019, 3, 2158-2170.

(2) Ferus, M.; Nesvornỳ, D.; Šponer, J.; Kubelík, P.; Michalčíková, R.; Shestivská, V.; Šponer, J. E.; Civiš, S. High-energy chemistry of formamide: A unified mechanism of nucleobase formation. Proceedings of the National Academy of Sciences 2015, 112, $657-662$.

(3) Persson, C. M. et al. Nitrogen hydrides in interstellar gas. Astronomy and Astrophysics 2010, 521, L45.

(4) van Dishoeck, E. F.; Jansen, D. J.; Schilke, P.; Phillips, T. G. Detection of the interstellar $\mathrm{NH}_{2}$ radical. Astrophysical Journal 1993, 416, L83.

(5) Swings, P.; McKellar, A.; Minkowski, R. Cometary emission spectra in the visual region. American Journal of Physics 1943, 98, 142.

(6) Sandford, S. A.; Bera, P. P.; Lee, T. J.; Materese, C. K.; Nuevo, M. In Photoinduced Phenomena in Nucleic Acids II: DNA Fragments and Phenomenological Aspects; Barbatti, M., Borin, A. C., Ullrich, S., Eds.; Springer International Publishing: Cham, 2015; pp 123-164.

(7) Ehrenfreund, P.; Charnley, S. B. Organic molecules in the interstellar medium, comets, and meteorites: a voyage from dark clouds to the early Earth. Annual Review of Astronomy and Astrophysics 2000, 38, 427-483.

(8) Bockelée-Morvan, D.; Crovisier, J.; Mumma, M.; Weaver, H. The composition of cometary volatiles. Comets Ii 2004, 1, 391-423. 
(9) Rubin, M.; Altwegg, K.; Balsiger, H.; Bar-Nun, A.; Berthelier, J.-J.; Bieler, A.; Bochsler, P.; Briois, C.; Calmonte, U.; Combi, M., et al. Molecular nitrogen in comet 67P/Churyumov-Gerasimenko indicates a low formation temperature. Science 2015, $348,232-235$.

(10) Herzberg, G.; Ramsay, D. A. Absorption spectrum of free $\mathrm{NH}_{2}$ radicals. The Journal of Chemical Physics 1952, 20, 347.

(11) Morino, I.; Kawaguchi, K. Fourier transform far-infrared spectroscopy of the $\mathrm{NH}_{2}$, NHD, and $\mathrm{ND}_{2}$ radicals. Journal of Molecular Spectroscopy 1997, 182, 428-438.

(12) Martin-Drumel, M. A.; Pirali, O.; Vervloet, M. Synchrotron based FT-FIR pure rotational spectroscopy of the $\mathrm{NH}_{2}$ radical in its two lowest vibrational states. The Journal of Physical Chemistry A 2014, 118, 1331-1338.

(13) Dressler, K.; Ramsay, D. A.; Herzberg, G. The electronic absorption spectra of $\mathrm{NH}_{2}$ and $\mathrm{ND}_{2}$. Philosophical Transactions of the Royal Society of London. Series A, Mathematical and Physical Sciences 1959, 251, 553-602.

(14) Ross, S.; Birss, F.; Vervloet, M.; Ramsay, D. The absorption spectrum of $\mathrm{NH}_{2}$ in the region 5300 to 6800 A.. Journal of Molecular Spectroscopy 1988, 129, 436-470.

(15) Schleipen, J.; ter Meulen, J.; Nemes, L.; Vervloet, M. New vibronic states of $\mathrm{NH}_{2}$ observed in ammonia photolysis. Chemical Physics Letters 1992, 197, 165-170.

(16) Dunlavey, S.; Dyke, J.; Jonathan, N.; Morris, A. Vacuum ultraviolet photoelectron spectroscopy of transient species. Molecular Physics 1980, 39, 1121-1135.

(17) Holzmeier, F.; Lang, M.; Fischer, I.; Hemberger, P.; Garcia, G.; Tang, X.; Loison, J.-C. Assignment of high-lying bending mode levels in the threshold photoelectron spectrum of $\mathrm{NH}_{2}$ : a comparison between pyrolysis and fluorine-atom abstraction radical sources. Physical Chemistry Chemical Physics 2015, 17, 19507-19514. 
(18) Willitsch, S.; Dyke, J. M.; Merkt, F. Rotationally resolved photoelectron spectrum of the lowest singlet electronic state of $\mathrm{NH}_{2}^{+}$and $\mathrm{ND}_{2}^{+}$: photoionization dynamics and rovibrational energy level structure of the $\tilde{a}^{+1} \mathrm{~A}_{1}$ state. Molecular Physics 2004, 102, $1543-1553$.

(19) Willitsch, S.; Merkt, F.; Kállay, M.; Gauss, J. Thermochemical properties of small open-shell systems: Experimental and high-level ab initio results for $\mathrm{NH}_{2}$ and $\mathrm{NH}_{2}^{+}$. Molecular Physics 2006, 104, 1457-1461.

(20) Barclay, V. J.; Hamilton, I. P.; Jensen, P. Vibrational levels for the lowest-lying triplet and singlet states of $\mathrm{CH}_{2}$ and $\mathrm{NH}_{2}^{+}$. The Journal of Chemical Physics 1993, 99, 97099719 .

(21) Stephens, J. C.; Yamaguchi, Y.; Schaefer III, H. F. The adiabatic and vertical ionization potentials of $\mathrm{NH}_{2}$ to the three lowest-lying states of $\mathrm{NH}_{2}^{+}$. Journal of Molecular Structure: THEOCHEM 1999, 461-462, 41-53.

(22) Gibson, S. T.; Greene, J. P.; Berkowitz, J. Photoionization of the amidogen radical. The Journal of Chemical Physics 1985, 83, 4319-4328.

(23) Nahon, L.; De Oliveira, N.; Garcia, G. A.; Gil, J. F.; Pilette, B.; Marcouillé, O.; Lagarde, B.; Polack, F. DESIRS: A state-of-the-art VUV beamline featuring high resolution and variable polarization for spectroscopy and dichroism at SOLEIL. Journal of Synchrotron Radiation 2012, 19, 508-520.

(24) Garcia, G. A.; Gans, B.; Tang, X.; Ward, M.; Batut, S.; Nahon, L.; Fittschen, C.; Loison, J.-C. Threshold photoelectron spectroscopy of the imidogen radical. Journal of Electron Spectroscopy and Related Phenomena 2015, 203, 25-30.

(25) Harper, O. J. VUV photoionisation of astrophysical molecules: fundamental and quantitative aspects. Ph.D. thesis, Université Paris-Saclay, 2020. 
(26) Hrodmarsson, H. R.; Garcia, G. A.; Nahon, L.; Loison, J.-C.; Gans, B. The absolute photoionization cross section of the mercapto radical (SH) from threshold up to 15.0 eV. Physical Chemistry Chemical Physics 2019, 25907-25915.

(27) Garcia, G. A.; de Miranda, B. K. C.; Tia, M.; Daly, S.; Nahon, L. DELICIOUS III: a multipurpose double imaging particle coincidence spectrometer for gas phase vacuum ultraviolet photodynamics studies. Review of Scientific Instruments 2013, 84, 53112 .

(28) Berkowitz, J. Experimental potential energy curves for $\mathrm{X}^{2} \Pi$ and ${ }^{2} \Sigma^{+}$states of $\mathrm{HF}^{+}$. Chemical Physics Letters 1971, 11, 21-26.

(29) Fillion, J.; Dulieu, F.; Baouche, S.; Lemaire, J.; Jochims, H.; Leach, S. Ionization yield and absorption spectra reveal superexcited Rydberg state relaxation processes in $\mathrm{H}_{2} \mathrm{O}$ and $\mathrm{D}_{2} \mathrm{O}$. Journal of Physics B: Atomic, Molecular and Optical Physics 2003, 36, 2767.

(30) Persky, A. The rate constant of the $\mathrm{F}+\mathrm{NH}_{3}$ reaction: Inverse temperature dependence. Chemical physics letters 2007, 439, 3-7.

(31) Atkinson, R.; Baulch, D.; Cox, R.; Crowley, J.; Hampson, R.; Hynes, R.; Jenkin, M.; Rossi, M.; Troe, J. Evaluated kinetic and photochemical data for atmospheric chemistry: Volume I-gas phase reactions of $\mathrm{O}_{x}, \mathrm{HO}_{x}, \mathrm{NO}_{x}$ and $\mathrm{SO}_{x}$ species. Atmospheric chemistry and physics 2004, 4, 1461-1738.

(32) Wiedmann, R.; Tonkyn, R.; White, M.; Wang, K.; McKoy, V. Rotationally resolved threshold photoelectron spectra of $\mathrm{OH}$ and OD. The Journal of chemical physics 1992, $97,768-772$.

(33) Dehmer, P. M.; Berkowitz, J.; Chupka, W. A. Photoionization of atomic oxygen from 920 to $650 \AA$ A. The Journal of Chemical Physics 1973, 59, 5777-5786.

(34) Harper, O. J.; Hassenfratz, M.; Loison, J.-C.; Garcia, G. A.; de Oliveira, N.; Hrodmars- 
son, H.; Pratt, S. T.; Boyé-Péronne, S.; Gans, B. Quantifying the photoionization cross section of the hydroxyl radical. The Journal of Chemical Physics 2019, 150, 141103.

(35) Harper, O. J.; Hassenfratz, M.; Loison, J.-C.; Garcia, G. A.; de Oliveira, N.; Hrodmarsson, H. R.; Pratt, S. T.; Boyé-Péronne, S.; Gans, B. Erratum: "Quantifying the photoionization cross section of the hydroxyl radical" [J. Chem. Phys. 150, 141103 (2019)]. The Journal of Chemical Physics 2020, 152, 189903.

(36) Samson, J. A. R.; Haddad, G. N.; Kilcoyne, L. D. Absorption and dissociative photoionization cross sections of $\mathrm{NH}_{3}$ from 80 to $1120 \AA$. The Journal of Chemical Physics 1987, 87, 6416-6422.

(37) Edvardsson, D.; Baltzer, P.; Karlsson, L.; Wannberg, B.; Holland, D. M. P.; Shaw, D. A.; Rennie, E. E. A photoabsorption, photodissociation and photoelectron spectroscopy study of $\mathrm{NH}_{3}$ and $\mathrm{ND}_{3}$. Journal of Physics B: Atomic, Molecular and Optical Physics 1999, 32, 2583-2609.

(38) Heays, A. N.; Bosman, A. D.; van Dishoeck, E. F. Photodissociation and photoionisation of atoms and molecules of astrophysical interest. Astronomy \& Astrophysics 2017, 602, A105.

(39) van Dishoeck, E. F. Chemistry in low-mass protostellar and protoplanetary regions. Proceedings of the National Academy of Sciences 2006, 103, 12249-12256.

(40) Gans, B.; Boyé-Péronne, S.; Broquier, M.; Delsaut, M.; Douin, S.; Fellows, C. E.; Halvick, P.; Loison, J.-C.; Lucchese, R. R.; Gauyacq, D. Photolysis of methane revisited at $121.6 \mathrm{~nm}$ and at $118.2 \mathrm{~nm}$ : quantum yields of the primary products, measured by mass spectrometry. Physical Chemistry Chemical Physics 2011, 13, 8140-8152.

(41) Meier, R.; Wellnitz, D.; Kim, S. J.; A'Hearn, M. F. The NH and CH bands of comet C/1996 B2 (Hyakutake). Icarus 1998, 136, 268-279. 
(42) Babcock, H. D. Chemical Compounds in the Sun. The Astrophysical Journal 1945, 102, 154 .

(43) Meyer, D. M.; Roth, K. C. Discovery of interstellar NH. The Astrophysical Journal 1991, 376, L49-L52. 


\section{Graphical TOC Entry}

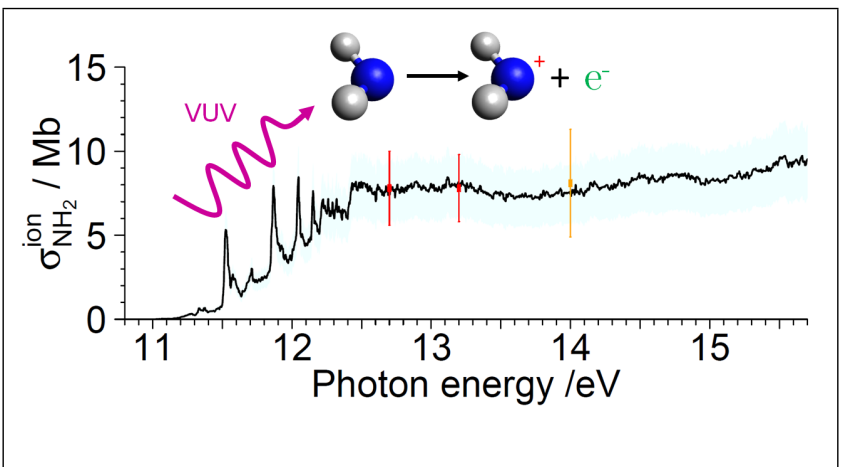

